INTERNATIONAL JOURNAL OF MULTIDisciplinARY RESEARCH AND ANALYSis

ISSN(print): 2643-9840, ISSN(online): 2643-9875

Volume 04 Issue 10 October 2021

DOI: 10.47191/ijmra/v4-i10-05, Impact Factor: 6.072

Page No.- 1377-1384

\title{
Entrepreneurship Practices and Profitability among Farmers in Jos, Nigeria
}

\author{
Atayi Abraham Vincent ${ }^{1}$, Gboyega Edward Babalola ${ }^{2}$ (PhD) \\ ${ }^{1}$ Department of Economics, Afe Babalola University, Ado Ekiti, Nigeria. \\ ${ }^{2}$ Department of Business Administration, Afe Bababola University
}

ABSTRACT: This study seeks to examine the relationship between Entrepreneurship practices and the level of profitability among farmers in Jos. The study covered small and medium scale farmer entrepreneurs within Jos North, Jos South and Jos East. A sample size of 518 was obtained from the population of 834 at $5 \%$ error tolerance and $95 \%$ level of confidence, using Simple Random Sampling. A self-structured questionnaire was used to collect data. 505(97.5\%) of the questionnaire distributed were returned. The study conducted a pre-test on the questionnaire to ensure the validity of the instrument. Data collected were presented in descriptive statistics and frequency tables. The study used financial ratios such as the gross profit margin, net profit margin, returns on assets, sales per year and total assets measures were used to measure the profitability. The average values for gross profit margin, net profit margin and returns on assets are $29.47 \%, 19.2 \%$ and $8.2 \%$ respectively; the result shows that an individual farmer in this study can boast of a high level of profit. The study recommends among other things that governments at all levels should work to create a more conducive environment for farmer entrepreneurs to make profitable investments in agriculture.

KEYWORDS: Profitability, Entrepreneurship Practice, Farmers, Descriptive Statistics and STATA 15

\section{INTRODUCTION}

As a vocation, entrepreneurship tries to identify possibilities, provide superior goods and services to intelligent clients, and profit in exchange for taking a risk. Many small and medium scale farmers and extension organizations, according to the Food and Agricultural Organization, acknowledge that until farmers become more entrepreneurial in their farm management, they will have little future (FAO, 2013). An entrepreneur is someone who creates products for the market. An entrepreneur is a self-driven and creative leader who is always seeking for new methods to improve and build his business for profit purposes (Alice et al; 2018). A business owner enjoys taking measured risks and is accountable for both profits and losses. An entrepreneur is obsessed with expanding his company and is always looking for new opportunities. Small and medium scale farmers are viewed as entrepreneurs around the world, and they have demonstrated extraordinary adaptability (FAO, 2013). They're attempting to find a more efficient way to manage their crops. They experiment with novel crops and cultivars, better animals, and alternative technology to boost productivity, diversify production, reduce risk, and boost profitability. They've learned to take calculated risks in order to expand or create new markets for their products, and they've become more market-oriented as a result (David, 2012).

The neglect of agriculture and an increasing reliance on a mono-cultural economy based on oil are among the historical causes of Nigeria's economic crisis. Agriculture has a significant impact on a country's social and economic base. Food and raw materials are also provided by agriculture to industry. Nigeria's non-oil exports are heavily based on agriculture. It is feasible to have a strong and productive agricultural industry, which may help a country feed its rising population, provide jobs, increase foreign revenue through agricultural exports, and provide raw materials for businesses (Oluwasanmi, 2011). Agriculture, because of its multifunctional nature, has a multiplier effect on any nation's socioeconomic and industrial fabric. According to economic history, an agrarian revolution is a necessary precursor for progress (Atayi et al; 2021). Agriculture has the ability to serve as a springboard for industrial and economic development in a country. Agricultural activities are commonly concentrated in rural areas that need to be transformed, redistributed, and socially developed (Stewart, 2000).

\section{LITERATURES REVIEW}

(Garba, 2019) points out that entrepreneurship can imply different things to different people, and that different people have different conceptual ideas on it. Despite these differences, there are certain commonalities, such as taking risks, being innovative, 


\section{Entrepreneurship Practices and Profitability among Farmers in Jos, Nigeria}

having opportunities, and reaping the benefits. It is described as the practice of developing new firms or enhancing existing ones in response to identified opportunities (Anh \& Harald, 2016). Economists say entrepreneurship is a tremendous economic force that allows people to look for opportunities where others see insurmountable obstacles. It's the practice of pooling resources, labor, and other assets to boost their value. Entrepreneurship signifies different things to different people, according to (Anh \& Harald, 2016). It also has distinct conceptual viewpoints.

Entrepreneurship is defined as the mobilization of economic resources to start a new business, identify new business opportunities, or rejuvenate an existing business for profit under private ownership in uncertain and risky circumstances (Harbi, Grolleau \& Bekir, 2011). Moreover, entrepreneurship is a process that can culminate in the creation of a single business or entrepreneur with the primary purpose of benefitting from scarce resources, usually under private control (Forsman, 2011). Entrepreneurship, on the other hand, is concerned with generating regular cash flow in the future for a group of people or a single individual via the application of initiative, innovation, and imagination, with the goal of lowering risk and maximizing profits over time (Forsman 2011, and GEM, 2014). Furthermore, (Baumol, 2014) defined entrepreneurship as the creation or exploitation of business opportunities, as well as the identification of these opportunities through the construction of new businesses.

Around a century ago, economists from Adam Smith to Marshall considered entrepreneurship as a system of structured knowledge, but they didn't use the phrase. To characterize various business operations that are now recognized as entrepreneurship, they used terms like employer, master, merchant, and undertaker. Cantillon was the first to develop the term "entrepreneur" (Murthy, 1989), and it has since received widespread recognition in economic literature. The definition of "entrepreneur" has received a lot of attention. Schumpeter (1959) defined entrepreneurs as "innovators." According to him, entrepreneurship is the "carrying out of novel combinations we call enterprise," and entrepreneurs are the people who do it. The new combinations concentrate on five aspects: the introduction of new aims, new production processes, the opening of new markets, new raw material supply sources, and new industrial organizations.

Entrepreneurship was definitely of the inventive and imitating type that sped up the development process for the West, the Soviet Union, and Japan in Asia. People in developing countries are more aware of entrepreneurship's importance in attaining rapid economic growth as a result of its involvement in the development of Western countries. People have begun to realize that growing the country's quantitative and qualitative entrepreneurship is critical to achieving the country's development goals. In qualitative entrepreneurship, the emphasis is on innovating, whereas in quantitative entrepreneurship, the emphasis is on mimicking. Both of these factors contribute to the growth of a child. It is also commonly understood that a country's resources for example, labor, technology, capital, and raw materials remain untapped in the absence of active and dynamic entrepreneurs who can organize the multiple forces of production (Baumol, 2014).

Entrepreneurship is defined as the mobilization of economic resources to start a new business, identify new business opportunities, or rejuvenate an existing business for profit under private ownership in uncertain and risky circumstances (Adenutsi, 2009). Moreover, entrepreneurship is a process that can culminate in the creation of a single business or entrepreneur with the primary purpose of benefitting from scarce resources, usually under private control (Hussain et al, 2014). Entrepreneurship, on the other hand, is concerned with generating regular cash flow in the future for a group of people or a single individual via the application of initiative, innovation, and imagination, with the goal of lowering risk and maximizing profits over time (Adenutsi, 2009 \& Hussain et al., 2014).

\section{Some of the Basic Characteristics of an Entrepreneur, According To Mustapha (2013):}

Creativity is the catalyst for the creation of new products, services, and business models. It's a passion to progress and invent. Learning, questioning, and thinking beyond the box is a process that lasts a lifetime. Dedication: This is what drives an entrepreneur to work long hours, sometimes even seven days a week, to get their firm off the ground, especially in the beginning. In order to be successful, hard labor must be combined with planning and ideas. Everything is feasible simply because of your commitment. Determinant is defined as a strong drive to succeed. It necessitates perseverance and the ability to recover from setbacks. It persuades the owner of the company to go above and beyond the call of duty. A true entrepreneur isn't exclusively motivated by profit. Money can be a motivator, but so can success. Flexibility refers to a company's capacity to react swiftly to changing market conditions. It's holding on to a dream but also taking into account commercial realities. Customers sought a barbershop when a businessman opened a supply store, folklore has it. Rather than risk losing these consumers, the entrepreneur modified his concept to meet their requirements. Leadership is defined as the ability to make decisions and set goals. It's the ability to see things through to the end to guarantee that rules are followed and objectives are met. Entrepreneurs are motivated by their passion, which is what first got them started. It enables business owners to persuade others to believe in their ideas. It won't 


\section{Entrepreneurship Practices and Profitability among Farmers in Jos, Nigeria}

replace planning, but it will assist them in staying on track and persuade others to consider their goals. Rigorous preparation eliminates risk and ambiguity, giving you peace of mind. Aspects such as expertise are also taken into account. You can listen without being swayed or intimidated when you have self-confidence. Smartness is defined as a combination of common sense and knowledge or experience within a linked organization or endeavor. The former provides you with sound judgment, while the latter provides you with information. Many people are smart but don't realize it. A household budget can be properly managed by someone with good organizational and financial skills. Intelligence is affected by both schooling and life experiences.

It becomes more challenging as the farm business expands. To meet the demands of rising complexity, farmer-entrepreneurs must continue to improve their managerial skills. They recognize the importance of honing their agricultural business management skills. Marketing is a crucial skill because revenue is based on it. Due to the significant level of risk involved in entrepreneurial farming, risk management is essential. Financial management is critical since profit can only be anticipated if revenue and costs are correctly reported. Labor management becomes increasingly important as the agriculture industry expands and more people are hired. Both in terms of production and risk management, this is critical. Hiring the incorrect person can swiftly turn revenues into losses. Above all, to ensure profitability and competitiveness, all of these disciplines require a sensible, integrated management style.

Agriculture accounts for over $38 \%$ of Nigeria's GDP and employs over $70 \%$ of the country's active labor force, therefore efforts to improve Nigerians' lives must be strategically centered on the agricultural sector (NBS, 2018). This is especially true if crude oil, which has long been a major source of revenue for the government, continues to fall out of favor as a result of overproduction, alternative green fuels, and other factors. Apart from crude oil, which has decreased in price by more than half in only two months, agriculture is Nigeria's only viable option. The lengthy period of neglect in agriculture could be coming to an end. Some believe that the price of crude oil will never fully recover, and that it will even fall further, forcing Nigeria to return to agriculture, which is regarded to offer better opportunities than crude oil.

Increased agricultural output is a crucial aspect in alleviating poverty and boosting rural farmers' well-being. On a micro level, increased farm revenue, food security, poverty reduction, and enhanced rural household welfare would result, while on a macro level, inclusive industry growth and economic advancement would result. According to (Kuznet, 1964), improvements in agricultural production can aid and sustain industrial development in a number of ways. It enables the agriculture sector to shift workers to the nonagricultural sector while still providing the nonagricultural sector's food needs. It also boosts agricultural revenue and gives rural populations the financial means to buy industrial items. Furthermore, it aids the agriculture sector in providing affordable food to industrial workers, hence increasing firm profitability. To boost agricultural productivity, Nigerian administrations have implemented a number of policies and measures.

\section{THEORETICAL FRAMEWORK}

This study adopted Schumpeter's theory of Entrepreneurship. And this is because it looked at entrepreneurship practices as they relate to economic growth through increased productivity as a result of entrepreneurial activities through innovation, and in this case, the emphasis is on entrepreneurship practices and profitability among farmers. The equations below explain how an entrepreneur can increase his productivity and profit by engaging in entrepreneurial activities powered by innovation investment. An entrepreneur's resource constraint equation is as follows:

$Y_{t}=L_{t}+K_{t}+R_{t}$

Where;

$Y_{t}=$ growth (output)

$L_{t}=$ labour

$K_{t}=$ intermediate good product

$R_{t}=$ research to continue to engage in entrepreneurial activities

$Y_{t}=\left(A_{t} L_{t}\right)^{1-\alpha} K_{t}$

$A_{t}=$ productivity

$K_{t}$ =capital used 


\section{Entrepreneurship Practices and Profitability among Farmers in Jos, Nigeria}

$L_{t}=$ labour/employment

Entrepreneurship is an act of innovation that raise the productivity $\left(A_{t}\right)$, for each productivity, there is an entrepreneur who has an opportunity to attempt an innovation. So if entrepreneurship is successful, it will create a new version of entrepreneurial intermediate product activity which is more productive than previous version (period before entrepreneurship practice) Thus, productivity increases from $A_{t-1}$ to $A_{t}$ as a result of entrepreneurship practices and

$\delta<1$, so

$A_{t}=\delta A_{t-1}$.

With entrepreneur success/ failure, productivity evolves as equation (3) below, but here we assume success for the entrepreneur $A_{t}=\left[\begin{array}{l}\delta A_{t-1} \\ A_{t-1}\end{array}\right]$

Where;

$\delta A_{t-1}=$ when entrepreneur is successful

$A_{t-1}=$ when entrepreneur fails

In order for entrepreneur to succeed, they must invest in entrepreneurial activities with probability $Z_{t}$ such that Entrepreneurship Activities (EA) is expressed as equation (4)

$E A=C\left(Z_{t}\right) A_{t-1}$

Equilibrium Production and Profit

The objective function of the entrepreneur is expressed as

$\max k_{t} l_{t}\left\{\left(A_{t} L\right)^{1-\alpha} K^{\alpha} L-W_{t} L_{t}-r_{t} k_{t}\right\}$

Inverse demand for $K_{t}$ in the case of equation (5) is

$r_{t}=\delta Y_{t} / \delta K_{t}=\alpha\left(A_{t} L\right)^{1-\delta} K^{\alpha-1}$

For employment or labor

$w_{t}=(1-\alpha) A_{t}^{1-\alpha} L^{-\alpha} K_{t}^{\alpha}$

It is assumed that;

$l_{t}=L$

An entrepreneur with productivity $A_{t}$ taking the demand as given will maximize profit $\pi\left(A_{t}\right)$ $\pi\left(A_{t}\right)=\max _{k_{t}}\left[\alpha\left(A_{t} L\right)^{1-\alpha} K^{\alpha}-k_{t}\right]$

$\pi\left(A_{t}\right)=\pi A_{t} L$

$\pi=(1-\alpha) \alpha^{1+\alpha /} 1-\alpha$

Equilibrium of Entrepreneurship Intensity practices

$$
A_{t}=\left\{\begin{array}{l}
\delta A_{t-1} \ldots \ldots \ldots \ldots . . Z_{t} \\
A_{t-1} \ldots \ldots \ldots \ldots \ldots \ldots 1-Z_{t}
\end{array}\right.
$$

Where $Z_{t}$ captures the entrepreneurship intensity

If the entrepreneur choses to intensify entrepreneurship Activities (EA) to maximize profit, then we have;

$\max _{z_{t}}\left\{Z_{t} \pi\left(\delta A_{t-1}\right)-C\left(Z_{t}\right) A_{t-1}\right\}$

$=\max \left\{Z_{t} \pi \delta L-C\left(z_{t}\right)\right\}$

$=c\left(z_{t}\right)$ 


\section{Entrepreneurship Practices and Profitability among Farmers in Jos, Nigeria}

$=\pi \delta L$

Therefore, equation 13 below is the equilibrium of entrepreneurship intensity

$Z_{t}=z=\pi \delta L$

\section{METHODOLOGY OF THE STUDY}

This study employed the use of primary data and secondary data. The primary data were obtained from questionnaire while the secondary were collected from the Central Bank of Nigeria, National Bureau of Statistics, Bank of Industry, Small and Medium Enterprise Development Agency of Nigeria, Journals and Text books, internet etc.

\section{Model Specification}

The traditional performance indicators, which are the financial ratios such as the gross profit margin, net profit margin, returns on assets, sales per year and total assets measures were presented using descriptive statistics such as mean, standard deviation, minimum and maximum. The financial ratios are expressed as follows;

The gross profit margin $=\frac{\text { Annual Gross Profit }}{\text { Sales per Year }}$

Net profit Margin $=\frac{\text { Annual Net Profit }}{\text { Sales per Year }}$

Return on Assets $=\frac{\text { Annual Net Profit }}{\text { Asset }}$

Sales per Year $=$ (Average sales per month $\mathrm{x} 12 \mathrm{months})$

Total Assets $=$ Average Total Assets

\section{RESULT INTERPRETATION}

\section{Descriptive Statistics}

\section{Respondents' Socioeconomic and Demographic Characteristics}

Table 1 displays the respondents' socioeconomic characteristics in terms of gender, marital position, educational attainment, language, and religion. 371 respondents, or 73.5 percent of the total sample, are male, while 134 respondents, or 26.5 percent, are female, according to the gender distribution. Males outnumber females in this analysis, indicating that men are more likely to engage in agricultural business than females who engage in petty trading. When it comes to marital status, 268 respondents (53.1\%) are married monogamous, followed by 133 (26.3\%) who are married polygamous, 60 (11.9\%), 12 (2.4\%), and 8 (1.6\%) who are never married, widowed, and separated, respectively.

No education, elementary education, secondary education, and post-secondary education are the four educational levels of the respondents. According to table 1, only 6 respondents (1.2\%) have no education, $86(17.0 \%)$ have primary education, and 182 (36\%) respondents have secondary education. Many respondents (45.7 percent) have post-secondary education, indicating that many of the respondents have a sufficient level of education to understand the study's issue. Furthermore, many of the respondents spoke Hausa, the dominant language in the research area, with the remainder speaking Yoruba and Igbo languages (105 (20.8\%) and 107 (21.2\%), respectively. Finally, the findings suggest that the majority of respondents are Christians (315(62.4), Muslims (174(34.5), and traditional worshippers (16(3.2).

Table 1: The distribution of respondent's socioeconomic Status

\begin{tabular}{|l|l|l|l|}
\hline Items & $\begin{array}{l}\text { Frequency } \\
\text { (Percentage) }\end{array}$ & Item & $\begin{array}{l}\text { Frequency } \\
\text { (Percentage) }\end{array}$ \\
\hline Gender of the of the farm-owner & & Marital Status & \\
\hline Male & $371(73.5 \%)$ & never married & $60(11.9)$ \\
\hline Female & $134(26.5 \%)$ & married monogamous & $268(53.1)$ \\
\hline & & married polygamous & $133(26.3)$ \\
\hline & & Separated & $8(1.6)$ \\
\hline & & Divorced & $12(2.4)$ \\
\hline & & Widowed & $24(4.8)$ \\
\hline Language Spoken & & & \\
\hline
\end{tabular}


Entrepreneurship Practices and Profitability among Farmers in Jos, Nigeria

\begin{tabular}{|l|l|l|l|}
\hline Yoruba & $105(20.8)$ & no education & $6(1.2)$ \\
\hline Igbo & $107(21.2)$ & primary education & $86(17.0)$ \\
\hline Hausa & $231(45.7)$ & secondary education & $182(36.0)$ \\
\hline Others & $62(12.3)$ & post-secodary education & $231(45.7)$ \\
\hline & & & \\
\hline Types of Religion & & & \\
\hline Christianity & $315(62.4)$ & & \\
\hline Islamic & $174(34.5)$ & & \\
\hline Traditional & $16(3.2)$ & & \\
\hline
\end{tabular}

Source: Field Survey, (2021)

\section{The Financial and Social Features of the Respondents}

The descriptive data of the respondents' financial, social, and financial performance is shown in Table 2-3. With a standard deviation of 7. 469, the respondents in panel an are on average 46 years old. The average age of the respondents is 29 years old, with a maximum age of 60 . The earliest year of business establishment, according to the respondents, was 1998, while others only started in 2017. With a maximum of twenty employees, the average number of employees is three. When it comes to personnel monthly pay, the average is N14677, with a standard deviation of N4633, and a range of N6000 to N27500. The average year of schooling for the respondents is 12 years, with a standard deviation of 4 years; the minimum and maximum years of schooling, respectively, are 2 and 20 years. The respondents' least and most monthly expenses are N18000 and N235000, respectively, in terms of average monthly expenses. The average spend is N49131, with a standard deviation of N32841. Similarly, the average monthly income is N163431, with a standard deviation of N100957, with the lowest and highest average earnings being N27000 and $\mathrm{N} 1015000$, respectively. With a standard deviation of 2, the average household size is 6 , while the smallest household size is 1 and the greatest household size is 12 . According to the health indices, the average body weight and height are $69.98 \mathrm{~cm}$ and $1.57 \mathrm{~m}$, respectively.

Table 2: The distribution of the financial and socio status of the respondents

\begin{tabular}{|l|l|l|l|l|}
\hline Items & Mean & Std. Deviation & Minimum & Maximum \\
\hline Age of the respondents & 46.26 & 7.469 & 29 & 60 \\
\hline Year of establishment & 2008.70 & 5.197 & 1998 & 2017 \\
\hline Number of employees & 3.41 & 2.510 & 1 & 20 \\
\hline Average salary of a staff per month & 14677.72 & 4633.409 & 6000 & 27500 \\
\hline Years of schooling & 12.49 & 3.961 & 2 & 20 \\
\hline Average monthly expenditure & 49131.09 & 32841.462 & 18000 & 235000 \\
\hline Average monthly income & 163431.7 & 100957.655 & 27000 & 1015000 \\
\hline Household size & 5.58 & 2.339 & 1 & 12 \\
\hline body weight & 69.98 & 4.695 & 57 & 78 \\
\hline Height in cm & 1.5662 & 0.11227 & 1.30 & 1.78 \\
\hline No of observation & 505 & & & \\
\hline
\end{tabular}

Source: Field Survey, (2021)

According to panel b of table 4.3, the average gross profit each year is N1296910, with a standard deviation of N1128011, and the minimum is N1000000 and the maximum is N5000000. Net profit fluctuates between N80000 and N4000000, with an average of N878970. The average daily sales are N22085 with the lowest and highest sales being N2800 and N300000, respectively. The total assets of the respondents range between $\mathrm{N} 350,000$ and $\mathrm{N} 100,000,000$, with an average of $\mathrm{N} 1,203,287.13$ and a standard deviation of $\mathrm{N} 1,321,322$. The series has considerable variations, as demonstrated by the differences between the minimum and maximum values, according to the statistical properties of these variables. Furthermore, the standard deviation suggests a narrower dispersion in the series.

Table 3: The distribution of the financial performance of the respondents

\begin{tabular}{|l|l|l|l|l|}
\hline Items & Mean & Std. Deviation & Minimum & Maximum \\
\hline Gross profit per annum & 1296910.89 & 1128011.297 & 100000 & 5000000 \\
\hline Net profit per annum & 878970.30 & 782692.829 & 80000 & 4000000 \\
\hline
\end{tabular}


Entrepreneurship Practices and Profitability among Farmers in Jos, Nigeria

\begin{tabular}{|l|l|l|l|l|}
\hline Average sale per day & 22085.94 & 37111.650 & 2800 & 300000 \\
\hline Average Total Assets & 1203287.13 & 1321322.422 & 350000 & 100000000 \\
\hline Average total liability & 404821.79 & 529295.085 & 20000 & 3750000 \\
\hline No of observation & 505 & & \\
\hline
\end{tabular}

Source: Field Survey, (2021)

The major characteristics of the financial ratios variables used to assess the success of retail farmers as entrepreneurs are summarized in Table 3. The average gross profit margin generated by farmers, according to this study, is 0.297447 , indicating that 29.47 percent of revenue is left over to cover basic operating costs, which primarily include salary, taxes, and general business expenses such as licenses fees, utilities, insurance, rent, advertising, and other farm-related costs. Similarly, after deducting all basic operating expenses, the average net profit margin is 0.191501 , which represents the remaining 19.2 percent of earnings. The minimum and greatest values are 0.06 and 0.44 , respectively, with a standard deviation of 0.159061 . As indicated in the table, the average return on asset, total asset, and sales per year are 0.082715 (8.2\%), N13800000, and 5671129, respectively. The average rate of return on asset is used to estimate the feasibility and sustainability of farming companies in this study. As indicated by the gross and net profit margins, the average return on asset implies a strong return on investment, which may maintain and retain these farmers in business.

The series' narrow standard deviation spread suggests that individual entrepreneurs' profit margins and other profitability metrics are quite close to the average value. As a result, there isn't much of a difference between each farmer's financial ratios. A net profit margin of more than $10 \%$, according to Maheshwari (2012), implies satisfactory outcomes. Financial ratios are also favorable, showing a rising profit trend, as evidenced by the results, which include a higher profit margin, demonstrating how efficiently these organizations manage their expenses. The profit margin study, at a glance, illustrates how much profit these farmers make on each kobo of revenue. This higher gross profit margin indicates that they make a decent profit on sales while keeping overhead costs under control. As a result, in this study, each individual farmer can boast of good financial success.

Table 4: Financial performance Indicators of farmers

\begin{tabular}{|l|l|l|l|l|}
\hline Variable & Mean & Std. Dev. & Min & Max \\
\hline Gross Profit Margin & 0.297447 & 0.159061 & 0.066667 & 0.6666667 \\
\hline Net Profit Margin & 0.191501 & 0.087172 & 0.06 & 0.4444444 \\
\hline Sales Per Year & 5671129 & 6349576 & 840000 & 90000000 \\
\hline Return on Assets & 0.082715 & 0.037771 & 0.016103 & 0.1807229 \\
\hline Average total Assets & 13800000 & 13700000 & 1000000 & 213000000 \\
\hline
\end{tabular}

Source: Computed from STATA 15, (2021)

\section{DISCUSSION OF FINDING}

As the result reveals, the viability and sustainability of agricultural operations in this study is determined by the average rate of return on asset, and the economic intuition above is consistent with this goal. The average return on asset indicates a significant return on investment, as evidenced by the gross and net profit margins, which may keep these farmers in business. The narrow standard deviation range of the series shows that individual entrepreneurs' profit margins and other profitability metrics are quite close to the average value. As a result, there isn't much of a difference in the financial ratios of any farmer. According to Maheshwari (2012), a net profit margin of more than $10 \%$ indicates satisfactory results. Financial ratios are also good, showing an upward profit trend, as evidenced by the results. The profit margin is higher, demonstrating the efficiency with which these farming companies manage their expenses. The profit margin study, at a glance, illustrates how much profit these farmers make on each kobo of revenue. This higher gross profit margin indicates that they make a decent profit on sales while keeping overhead costs under control. As a result, a single farmer in this study can boast of a high level of financial success combined with the appropriate attitude toward profitability, by so doing improving their standard of living.

\section{CONCLUSION/RECOMMENDATIONS}

The results of the answer analysis suggested that many farmers had a lot of room to grow their entrepreneurship operations. This is because the majority of farmers believe that farming businesses with a high turnover are viable. Apart from the high profit margins in the farming business, many farmers also noted that agricultural enterprises contribute greatly to productivity and that farmers can grow from a small to a large-scale operation. Farmers have a higher profit margin, which reflects how efficiently they 


\section{Entrepreneurship Practices and Profitability among Farmers in Jos, Nigeria}

manage their expenses. And because they have a higher gross profit margin, they can make a decent profit on sales while keeping overhead costs low. As a result, in this study, each individual farmer can boast of good financial success.

The research therefore recommends among other things that to improve their financial performance, governments at all levels should work to create a more conducive environment for farmer entrepreneurs to make profitable investments in the production and distribution of inputs for small and medium scale farmers in live-stock farming, such as improved starter materials and animal health drugs. The government's major responsibility should be to closely monitor all fertilizer quality standards (domestic and foreign) to ensure that only certified items reach small and medium scale farmer entrepreneurs. Mobilizing, promoting, and motivating the organized private sector to actively participate in raising awareness for entrepreneurship innovation among farmers will improve farmers' overall profit.

\section{REFERENCES}

1) Abdul, M., Ismail, H., \& Mustapha, M. (2013). Halal food certification: Case of Malaysian SME entrepreneurs. China-USA Business Review, 12(2).

2) Adenutsi, D. E. (2009). Entrepreneurship, job creation, income empowerment and poverty reduction in low-income economies.

3) Anh T.P and Harald V. K 2016. A conceptual model of social entrepreneurial intention based on the social cognitive career theory. Asia Pacific Journal of Innovation and Entrepreneurship ISSN: 2398-7812

4) Atayi A. V, Ilugbusi . S, Nkire N. L \& Akanmu A. A, (2021) Entrepreneurship, Agricultural Value-Chain and Exports in Nigeria. United International Journal for Research and Technology 2(8).UIJRT.COM

5) Baumol WJ (2014) Stimulating growth amid recession: entrepreneurship, innovation, and the keynesian revolution. J Jpolmod 36: 629-635.

6) David Kahan, 2012, Entrepreneurship in Farming, a United Nations project.

7) Dorin, C., \& Alexandru, G. S. (2014). Dynamics of the entrepreneurship concept. Literature review. The annals of the University of Oradea, 23(1), 443-451.

8) FAO (2013).World Food and Agriculture Electronic File.www.fao.org/corp/statistics/en

9) Forsman H (2011) Innovation capacity and innovation development in small enterprises. A comparison between the manufacturing and service sectors. J Respol 40: 739-750

10) Garba, A. S., Kabir, I., \& Mahmoud, M. A. (2019). Entrepreneurial Orientation and Growth Potential of Microenterprises in Northwest, Nigeria. Journal of Developmental Entrepreneurship, 24(02), 1950011.

11) GEM (Global Entrepreneurship Monitor) (2014) Informe gem españa 2013 (gem spain report 2013). Red española de equipos regionales spanish network of regional teams, Spain

12) Harbi SE, Grolleau G, Bekir I (2011) Entrepreneurship and growth: What causes what? Advances in the study of entrepreneurship. Inno Econ Grow 22: 73-91.

13) Izediuno, O. L., Alice, O. T., \& Daniel, O. A. (2018). Analytical review of small and medium scale enterprises in Nigeria. International Journal of Small Business and Entrepreneurship Research, 6(2), 32-46.

14) Murthy, N. (1989a).Entrepreneurship in Small Towns, In Samuddin (ed) Entrepreneurship Development in India, Mittal Publication, Delhi 4.

15) National Bureau of Statistics, Data and Analysis of Youth Unemployment in Nigeria. National Bureau of Statistics (NBS), Statistical Bulletin, 2018.

16) Oluwasanmi, H.A. (2011): Agriculture and Nigeria's Economic Development: Ibadan University Press.

17) Schumpeter, J.A. (1959). The Theory of Economic Development Massachusetts. Harvard University Press, Cambridge.

18) Stewart, R. (2000): Welcome Address proceedings of the $7^{\text {th }}$ world sugar farmers Conference.

Durbai.www.sugaronline.com/sugarindustry/index.htm. 